ARD

\title{
Association between weight or Body Mass Index and hand osteoarthritis: a systematic review
}

Erlangga Yusuf, Rob Nelissen, Andreea loan-Facsinay, Vedrana Stojanovic-Susulic, Jeroen DeGroot, Gerjo van Osch, Saskia Middeldorp, TWJ Huizinga and Margreet Kloppenburg

Ann Rheum Dis published online 31 May 2009; doi:10.1136/ard.2008.106930

Updated information and services can be found at:

http://ard.bmj.com/cgi/content/abstract/ard.2008.106930v1

These include:

\section{Rapid responses You can respond to this article at:}

http://ard.bmj.com/cgi/eletter-submit/ard.2008.106930v1 $\begin{array}{cl}\text { Email alerting } & \begin{array}{l}\text { Receive free email alerts when new articles cite this article - sign up in the box at the } \\ \text { service }\end{array} \text { top right corner of the article }\end{array}$

\section{Notes}

Online First contains unedited articles in manuscript form that have been peer reviewed and accepted for publication but have not yet appeared in the paper journal (edited, typeset versions may be posted when available prior to final publication). Online First articles are citable and establish publication priority; they are indexed by PubMed from initial publication. Citations to Online First articles must include the digital object identifier (DOIs) and date of initial publication.

To order reprints of this article go to:

http://journals.bmj.com/cgi/reprintform

To subscribe to Annals of the Rheumatic Diseases go to:

http://journals.bmj.com/subscriptions/ 
Association between Weight or Body Mass Index and Hand Osteoarthritis: A Systematic Review

Erlangga Yusuf $\mathrm{MD}^{1}$, Rob G Nelissen MD $\mathrm{PhD}^{2}$, Andreea Ioan- Facsinay $\mathrm{PhD}^{1}$, Vedrana Stojanovic-Susulic $\mathrm{PhD}^{3}$, Jeroen DeGroot $\mathrm{PhD}^{4}$, Gerjo van Osch $\mathrm{PhD}^{5}$, Saskia Middeldorp MD $\mathrm{PhD}^{6}$, Tom WJ Huizinga MD $\mathrm{PhD}^{1}$, Margreet Kloppenburg MD PhD ${ }^{1}$

From:

1. Department of Rheumatology, Leiden University Medical Center, Leiden, The Netherlands

2. Department of Orthopedics, Leiden University Medical Center, Leiden, The Netherlands

3. Centocor, Inc. Horsham, Pennsylvania, USA

4. TNO Quality of Life, Business Unit Medical Research, Leiden, The Netherlands

5. Department of Orthopedics, Erasmus MC, Rotterdam, The Netherlands

6. Department of Clinical Epidemiology and Department of General Internal Medicine, Leiden University Medical Center, Leiden, The Netherlands

\section{Corresponding Author:}

Erlangga Yusuf, M.D, Department of Rheumatology

Leiden University Medical Center. C1-46, Postbus 9600, 2300 RC Leiden, The

Netherlands

E-mail: e.yusuf@lumc.nl

Key words: hand; osteoarthritis; overweight; weight; systematic review

Word count: abstract 235, manuscript 1997 


\begin{abstract}
Objective:

To investigate the association between weight or Body Mass Index (BMI) and the development of hand osteoarthritis (OA).
\end{abstract}

\title{
Methods:
}

Systematic review of observational studies. Medical databases were searched up to April 2008. Articles which presented data on the association between weight and hand OA were selected. The qualities of these studies were then assessed by two independent reviewers using a 19 criteria scoring system. Using the mean scores of all studies as cutoff value, the studies were deemed as high- or low- quality. Study quality and study designs were combined to determine the level of evidence using best-evidence synthesis which consisted of five levels of evidence.

\section{Results:}

From the 25 studies included, two had cohort, three case-control and 20 cross-sectional study designs. Fifteen studies were considered as high-quality studies. Of these highquality studies, one cohort, two case-control and seven cross-sectional studies showed a positive association between weight or BMI and hand OA. Based on three high-quality studies with preferred study designs (one cohort and two case-control) with a positive association, the level of evidence of the association between overweight and developing hand OA is moderate. The approximate risk ratio of this association is 1.9.

\section{Conclusion:}

Weight or BMI is associated with hand OA development. The level of evidence of published studies is moderate according to best-evidence synthesis. Further high-quality cohort or case-control studies are needed to elucidate the role of weight in hand OA. 


\section{Introduction}

Osteoarthritis (OA) is the most common joint disease. Its etiology is largely unknown and no disease-modifying treatment exists.(1) Overweight is recognized as a risk factor for developing knee OA. Being overweight increases the mechanical forces across weightbearing joints and leads to OA.(2) Whether this is the sole explanation, is challenged by some studies that showed that overweight is also associated with hand OA of non-weightbearing joints, like hand joints.

In a recommendation for the diagnosis of hand OA by a task force of the European League Against Rheumatism, obesity was described as a risk factor for hand OA.(3) This was based only on four studies. However, in two narrative reviews $(1 ; 4)$ the association of overweight and hand OA was inconsistent, but narrative reviews have some shortcomings like potential selective inclusion of papers without systematic quality assessment of selected studies.(5) Furthermore, since the latest narrative review, several new studies on this topic have been published.

To summarize data on the association between weight and hand OA development which would give more insight in the etiology of OA and give consideration whether prevention of overweight and loosing weight could be a preventive treatment of hand OA, we performed a systematic review of available studies.

\section{Material and Methods}

Identification of studies

Together with a medical librarian we searched medical databases up to April 2008 for studies with data on the association between weight or Body Mass Index (BMI) and hand OA (Appendix I, online supplemental file). No language restriction was applied. Additional articles were searched on the reference lists of identified articles and in Google Scholar.

\section{Inclusion and exclusion criteria}

Two reviewers, EY, a PhD student, and MK, a senior rheumatologist, independently read abstracts of all retrieved references for obvious exclusions and subsequently read the full text of remaining references. Studies with: (i.) data on the association between weight or $\mathrm{BMI}$ and hand OA; (ii.) participants suffering from clinical or radiographic or selfreported hand OA, were included. Hand OA was defined as involvement of at least one hand joint. Reviews, abstracts, letters to the editor, case reports, case series and studies investigated other musculoskeletal disease than OA, were excluded. In case of multiple publications of the same patient population, the publication with the largest study population was selected.

\section{Data extraction}

Following data were extracted: (i.) study population (patient characteristics, population size, gender, and age) (ii.) exposure (weight (kilograms) or BMI $\left(\mathrm{kg} / \mathrm{m}^{2}\right)$ or other methods) (iii.) outcome (methods of assessment of hand OA, reproducibility, blinding). 
(iv.) potential confounders (age, gender, smoking, hormone therapy, workload) (v.) association size (relative risk (RR) or odds ratio (OR)).

Assessment of study quality

The same reviewers independently evaluated the quality of the studies using 19 criteria based on previous systematic reviews in the area of musculoskeletal disorders $(6 ; 7)$ with a modification to evaluate studies on the association between weight and hand OA (Appendix II, online supplemental file). When the criterion was met in the article, ' 1 ' was given; otherwise ' 0 '. A ' 0 ' was also given when no information about the specific criterion mentioned in the article. Differences were solved by discussion. Maximum scores obtainable were 16 for cohort and case-control studies, and 13 for cross-sectional studies. Total scores per study were calculated as percentage of maximum obtainable scores.

\section{Rating the level of evidence}

We generated a Forest plot and summarized the evidence using the best-evidence synthesis based on the guidelines on systematic review of the Cochrane Collaboration Back Review Group.(8) This system is a method to summarize evidence in observational studies where the study population, the assessment of exposure and outcomes, and the data analyses are heterogenic.(7) It has five levels of evidence (Table 1). It puts more weight on studies with a prospective cohort design where exposure truly precedes outcomes. The next preferred designs are case-control and cross-sectional, respectively. The mean of the quality scores of all studies was used to classify studies as high or low quality.

Table 1: Best-evidence synthesis used in this review (8).

\begin{tabular}{|l|l|}
\hline Strong & $\begin{array}{l}\text { General consistent findings were presented in multiple } \\
\text { high-quality cohort studies }\end{array}$ \\
\hline Moderate & $\begin{array}{l}\text { One high-quality cohort study and at least two high- } \\
\text { quality case-control studies, or when at least three high- } \\
\text { quality case-control studies show general consistent } \\
\text { findings }\end{array}$ \\
\hline Limited & $\begin{array}{l}\text { General consistent findings were found in a single cohort } \\
\text { study, or in maximum two case-control studies, or in } \\
\text { multiple cross-sectional studies }\end{array}$ \\
\hline Conflicting, & Less than $75 \%$ of the studies reported consistent findings \\
\hline No evidence & No study could be found \\
\hline
\end{tabular}

\section{Publication bias}

Publication bias was investigated by generating a Funnel plot. The association size of weight or BMI and developing hand OA on the horizontal axis was plotted against study population size on the vertical axis. Asymmetry in the Funnel plot suggests publication bias.(9) We determined symmetry visually. 


\section{Results}

Literature flow

From 472 identified references 27 were selected based on in- and exclusion criteria (Figure 1).(10-36) Additional search resulted in another 6 articles.(37-42) Seven articles were excluded $(11 ; 17 ; 25 ; 27 ; 32 ; 35 ; 41)$ due to overlap in study population. One study was represented by two publications $(20 ; 21)$, further referred to as (20). In total, 25 studies were included: two cohort $(13 ; 36)$, one case-control (30) and 20 cross-sectional studies $(10 ; 12 ; 15 ; 16 ; 18-20 ; 22-24 ; 26 ; 28 ; 31 ; 33 ; 34 ; 37-40 ; 42)$. Two studies $(14 ; 29)$ resembled a case-control design.

Characteristics of included studies (Appendix III, online supplemental file)

Eight studies investigated only women $(13 ; 14 ; 18 ; 23 ; 30 ; 34 ; 37 ; 38)$ and one $(22)$ only men Hand OA was diagnosed using radiographic criteria in 21 studies $(12-16 ; 18 ; 20 ; 22-$ $24 ; 26 ; 28 ; 30 ; 33 ; 34 ; 36-40 ; 42) ; 18$ of them used radiographic criteria only and three $(18 ; 30 ; 39)$ used radiographic and clinical criteria. Clinical criteria only were used in two studies (10;31), one of them (10) used the American College of Rheumatism criteria for hand OA. In two studies $(19 ; 29)$, hand OA was self-reported by the patients. 
Study quality assessment

The two reviewers agreed on 305 (90\%) of 340 criteria (Appendix IV, online supplemental file). The disagreements were solved in a single meeting and mostly concerned assessment of hand OA (criteria 9 and 10). The mean of quality scores was $63 \%$.

The participation rates in most studies were lower than $80 \%$ (criterion 5). One cohort study had limitations in the assessment of hand OA (criteria 9 and 10) and the follow-up (criteria 14 and 15). Two case-control studies had limitations in the assessment of hand OA (criterion 10). Moreover, two of three case-control studies had potential selection bias, being sampling bias (items 2 and 5). This bias was also commonly seen in cross-sectional studies.

\section{Associations shown in included studies}

Hand OA in at least one joint showed a statistically significant positive association with weight in 16 of $25(64 \%)$ studies.(12-16;18;20;26;30;31;33;34;37;38;40;42) The other nine studies showed a non-significant or no association. Fourteen of 25 studies $(10 ; 13 ; 14 ; 16 ; 18$ 20;24;28;30;31;34;36;39) presented association sizes as OR and RR values (Figure 2) giving an estimated pooled risk ratio of 1.9 for the positive association between (over)weight and development of hand OA. Three $(15 ; 31 ; 37)$ of these 16 studies showed a significant positive association in one gender, but a non-significant or no association in the other gender.

Six of nine studies $(12 ; 14-16 ; 18 ; 24 ; 39 ; 40 ; 42)$ investigating distal interphalangeal joints, two of eight $(12 ; 14-16 ; 36 ; 39 ; 40 ; 42)$ studies investigating proximal interphalangeal joints, one of four studies $(12 ; 22 ; 40 ; 42)$ investigating metacarpophalangeal joints and four of 12 studies $(12 ; 14-16 ; 20 ; 24 ; 28 ; 33 ; 36 ; 39 ; 40 ; 42)$ investigating first carpometacarpal joints showed a positive significant association with weight or BMI.

Levels of evidence

The level of evidence for a positive association between weight or BMI and hand OA is moderate. Fifteen of 25 included studies $(10 ; 13-16 ; 18 ; 20 ; 24 ; 28 ; 30 ; 31 ; 34 ; 36 ; 39 ; 42)$ were considered to be of high quality. Of two high-quality cohort studies $(13 ; 36)$ one (13) showed an RR of 3.12 (1.65-5.88); the second showed no association. Both high-quality case-control studies $(14 ; 30)$ reported a positive significant association, with an OR of 1.30(1.06-1.59) (14) and $8.3(1.2-56.5)(30)$. Of $11(10 ; 15 ; 16 ; 18 ; 20 ; 24 ; 28 ; 31 ; 34 ; 39 ; 42)$ high-quality cross-sectional studies, seven studies $(15 ; 16 ; 18 ; 20 ; 31 ; 34 ; 42)$ reported a positive association.

In a subgroup of studies which used radiographic criteria with or without clinical criteria for hand OA, 13 of 21 studies were deemed as high-quality. Ten $(13-16 ; 18 ; 20 ; 30 ; 31 ; 34 ; 42)$ of these 13 studies showed a positive association and the level of evidence remained moderate. In the subgroup of studies using radiographic criteria only (18 studies; of which 10 with highquality), seven $(13-16 ; 20 ; 34 ; 42)$ studies showed a positive association, but due to the lack of sufficient number of high quality cohort (only one study) and case-control (only one study) studies, the level was limited. The subgroup of clinical studies $(10 ; 31)$ showed conflicting level of evidence.

Using alternative cut-offs for methodological quality assessment (median or $25^{\text {th }}$ percentile) did not change the results. When using $75^{\text {th }}$ percentile as cut-off, few studies were retained leading to limited level of evidence.

\section{Publication bias}

We plotted the association sizes (OR and RRs) against the sample sizes of 14 studies to investigate publication bias (Figure 3 ). Visually, the plot was asymmetric. 


\section{Discussion}

This systematic review showed that the evidence for a positive association between weight or $\mathrm{BMI}$ and hand OA is moderate. This conclusion is based on three high-quality studies with preferred study designs. Moderate level of evidence did not change for the subgroup of studies investigated hand OA using radiographic criteria. When no best-evidence synthesis was performed, a pooled risk ratio was approximately 1.9, where $64 \%$ of published studies showed a positive association between (over)weight and hand OA.

The strength of a systematic review is the use of a focused research question, an extended search strategy and a pre-defined system to evaluate the quality of evidence. Here, we also use qualitative levels of evidence to give a conclusion when a summary of quantity statistic was not appropriate. Yet, this systematic review has some possible limitations which also reflect the limitations of the published studies. The first caveat is the heterogeneities in multiple aspects of the studies, like the definition of BMI, hand OA and study population. Studies categorized BMI in various ways, mainly based on the distribution of study population, such as tertiles and median or BMI as a continuous variable. Preferentially, cut-off of BMI 25 $\mathrm{kg} / \mathrm{m}^{2}$, as World Health Organization definition for overweight could be used.(43) However, this was performed only in a minority of studies. Included studies defined hand OA also in various ways, using radiographic and clinical criteria. Subgroup analysis of studies which used radiograph to make diagnosis of hand OA, however did not change the level of evidence. The level of evidence became conflicting when we performed a subgroup analysis in only two studies defined hand OA using clinical criteria. The lack of clinical studies might reflect the available evidence which suggests that radiography is a better method in defining hand OA in epidemiology studies.(4) Another heterogeneity which can be mentioned here is the study population. Although the most studies used mixed sex, a third of the included studies concerned only females. These heterogeneities lead to difficulties in comparing studies and in summarizing studies quantitatively. The second caveat of this review is the possibility of publication bias. However, when we examine the Funnel plot carefully, the asymmetry is caused by one study with large effect (30) This study also differs to other studies that it used hand OA based on clinical criteria supported by radiograph findings. The third caveat of this review is that theoretically, the criteria we used can influence the outcomes of this review. We used and modified criteria which were previously used in systematic reviews the musculoskeletal field, since no generally accepted set of criteria exist for methodological quality assessment in observational studies,.

The consequence of the moderate level of evidence of an association is that further research is likely to have an important impact.(44) Therefore, future studies, especially well-designed prospective cohort or case-control studies are called for, which should also investigate the etiological mechanisms of the association and temporal relationship between overweight or obesity and hand OA.

The pathogenesis of OA is largely unknown and no disease-modiying treatment exists, hence knowledge on the role of overweight in hand OA is of importance for understanding and treating (hand) OA. The association between overweight and hand OA suggests that also other factors than mechanical forces play a role. Some possible links between overweight and osteoarthritis have been proposed, like metabolic alteration, atherosclerosis and diabetes mellitus.(45) Fat tissues secrete pro-and anti-inflammatory adipo(cyto)kines, like leptin, which was observed in synovial fluid obtained from osteoarthritic joints.(46) Leptin's concentration in advanced osteoarthritic cartilage is significantly correlated with the BMI of the patients, and its level and pattern of expression were related to the grade of cartilage 
destruction. Obesity-associated atherosclerosis can also accelerated the OA process by the vascular disease in subchondral bone.(47) Lastly, in diabetes mellitus, advanced glycation end products (AGE) is formed and accumulated. AGE cross-linking damaged collagen network and lead to cartilage changes associated with osteoarthritis. This AGE formation is initiated not only by sugars but also by lipids.(48)

In summary, this is the first systematic review which investigated the association between weight and BMI and hand OA. The association is positive and the level of evidence is moderate. This calls for well-designed studies that further estimate the association as well as its underlying mechanisms.

\section{Acknowledgements}

The authors thank Drs. J. W. Schoones, medical librarian of Leiden University Medical Center for his assistance in performing literature search.

\section{Funding}

The study was financially supported by TI Pharma and Centocor, Inc.

\section{Exclusive License}

"The Corresponding Author has the right to grant on behalf of all authors and does grant on behalf of all authors, an exclusive licence (or non exclusive for government employees) on a worldwide basis to the BMJ Publishing Group Ltd to permit this article (if accepted) to be published in ARD and any other BMJPGL products and sublicences such use and exploit all subsidiary rights, as set out in our licence (http://ARD.bmjjournals.com/ifora/licence.pdf)."

\section{Figures List}

Figure 1: Results of the literature search

Figure 2. Forest plot showing the association sizes (odds ratios (OR) or relative risks (RR)) between (over)weight or BMI with hand osteoarthritis of the studies included, arranged by study design and quality scores (from high to low). The numbers in bracket represents the references. $\mathrm{n}$ represents number of study population. For information on the actual association sizes concerning used hand OA phenotype and BMI category see Appendix III (online supplemental file). Labeled with asterisk are studies which presented OR or RR as increase per unit BMI.

Figure 3. Funnel plot showing the relation between association sizes (odds ratios (OR) or relative risks (RR)) and sample size. The numbers represents the references of the studies. When studies presented multiple association sizes, the largest RR or OR concerning a cut-off at BMI $25 \mathrm{~kg} / \mathrm{m}^{2}$ was denoted. If this information were not available, association size of a cutoff at a higher BMI level was used. Preferentially, association sizes for radiographic hand OA and for men and women combined was presented. 
Reference List

(1) Felson DT, Chaisson CE. Understanding the relationship between body weight and osteoarthritis. Baillieres Clin Rheumatol 1997; 11(4):671-81.

(2) Hunter DJ, Felson DT. Osteoarthritis. BMJ 2006; 332(7542):639-42.

(3) Zhang W, Doherty M, Leeb BF, Alekseeva L, Arden NK, Bijlsma JW et al. EULAR evidence based recommendations for the diagnosis of hand osteoarthritis - report of a task force of the EULAR Standing Committee for International Clinical Studies Including Therapeutics (ESCISIT). Ann Rheum Dis 2008.

(4) Hart DJ, Spector TD. Definition and epidemiology of osteoarthritis of the hand: a review. Osteoarthritis Cartilage 2000; 8 Suppl A:S2-S7.

(5) Cook DJ, Mulrow CD, Haynes RB. Systematic reviews: synthesis of best evidence for clinical decisions. Ann Intern Med 1997; 126(5):376-80.

(6) Borghouts JA, Koes BW, Bouter LM. The clinical course and prognostic factors of non-specific neck pain: a systematic review. Pain 1998; 77(1):1-13.

(7) Lievense AM, Bierma-Zeinstra SM, Verhagen AP, van Baar ME, Verhaar JA, Koes $\mathrm{BW}$. Influence of obesity on the development of osteoarthritis of the hip: a systematic review. Rheumatology (Oxford) 2002; 41(10):1155-62.

(8) van TM, Furlan A, Bombardier C, Bouter L. Updated method guidelines for systematic reviews in the cochrane collaboration back review group

Spine 2003; 28(12):1290-9.

(9) Egger M, Davey SG, Schneider M, Minder C. Bias in meta-analysis detected by a simple, graphical test

BMJ 1997; 315(7109):629-34.

(10) Andrianakos AA, Kontelis LK, Karamitsos DG, Aslanidis SI, Georgountzos AI, Kaziolas GO et al. Prevalence of symptomatic knee, hand, and hip osteoarthritis in Greece. The ESORDIG study. J Rheumatol 2006; 33(12):2507-13.

(11) Bagge E, Bjelle A, Eden S, Svanborg A. Factors associated with radiographic osteoarthritis: results from the population study 70 -year-old people in Goteborg. J Rheumatol 1991; 18(8):1218-22.

(12) Bergstrom G, Bjelle A, Sundh V, Svanborg A. Joint disorders at ages 70, 75 and 79 years--a cross-sectional comparison. Br J Rheumatol 1986; 25(4):333-41.

(13) Carman WJ, Sowers M, Hawthorne VM, Weissfeld LA. Obesity as a risk factor for osteoarthritis of the hand and wrist: a prospective study. Am J Epidemiol 1994; 139(2):119-29.

(14) Cicuttini FM, Baker JR, Spector TD. The association of obesity with osteoarthritis of the hand and knee in women: a twin study. J Rheumatol 1996; 23(7):1221-6. 
(15) Cvijetic S, Campbell L, Cooper C, Kirwan J, Potocki K. Radiographic osteoarthritis in the elderly population of Zagreb: distribution, correlates, and the pattern of joint involvement. Croat Med J 2000; 41(1):58-63.

(16) Dahaghin S, Bierma-Zeinstra SM, Koes BW, Hazes JM, Pols HA. Do metabolic factors add to the effect of overweight on hand osteoarthritis? The Rotterdam Study. Ann Rheum Dis 2007; 66(7):916-20.

(17) Davis MA, Neuhaus JM, Ettinger WH, Mueller WH. Body fat distribution and osteoarthritis. Am J Epidemiol 1990; 132(4):701-7.

(18) Ding H. Association between overweight and dip osteoarthritis among middle-aged Finnish female dentists and teachers. Obesity Research and Clinical Practice 2008; 2(1):61-8.

(19) Grotle M, Hagen KB, Natvig B, Dahl FA, Kvien TK. Prevalence and burden of osteoarthritis: results from a population survey in norway

1. J Rheumatol 2008; 35(4):677-84.

(20) Haara MM, Manninen P, Kroger H, Arokoski JP, Karkkainen A, Knekt P et al. Osteoarthritis of finger joints in Finns aged 30 or over: prevalence, determinants, and association with mortality

Ann Rheum Dis 2003; 62(2):151-8.

(21) Haara MM, Heliovaara M, Kroger H, Arokoski JP, Manninen P, Karkkainen A et al. Osteoarthritis in the carpometacarpal joint of the thumb. Prevalence and associations with disability and mortality

J Bone Joint Surg Am 2004; 86-A(7):1452-7.

(22) Hochberg MC, Lethbridge-Cejku M, Plato CC, Wigley FM, Tobin JD. Factors associated with osteoarthritis of the hand in males: data from the Baltimore Longitudinal Study of Aging Am J Epidemiol 1991; 134(10):1121-7.

(23) Hochberg MC, Lethbridge-Cejku M, Scott WW, Jr., Plato CC, Tobin JD. Obesity and osteoarthritis of the hands in women Osteoarthritis Cartilage 1993; 1(2):129-35.

(24) Jones G, Cooley HM, Stankovich JM. A cross sectional study of the association between sex, smoking, and other lifestyle factors and osteoarthritis of the hand Journal of Rheumatology 2002; 29(8):1719-24.

(25) Kalichman L, Cohen Z, Kobyliansky E, Livshits G. Interrelationship between bone aging traits and basic anthropometric characteristics

American Journal of Human Biology 2002; 14(3):380-90.

(26) Kalichman L, Malkin I, Kobyliansky E. Association between physique characteristics and hand skeletal aging status Am J Phys Anthropol 2005; 128(4):889-95. 
(27) Kalichman L, Kobyliansky E. Age, body composition, and reproductive indices as predictors of radiographic hand osteoarthritis in Chuvashian women Scand J Rheumatol 2007; 36(1):53-7.

(28) Kessler S, Stove J, Puhl W, Sturmer T. First carpometacarpal and interphalangeal osteoarthritis of the hand in patients with advanced hip or knee OA. Are there differences in the aetiology?

Clin Rheumatol 2003; 22(6):409-13.

(29) Kujala UM, Leppavuori J, Kaprio J, Kinnunen J, Peltonen L, Koskenvuo M. Jointspecific twin and familial aggregation of recalled physician diagnosed osteoarthritis Twin Res 1999; 2(3):196-202.

(30) Oliveria SA, Felson DT, Cirillo PA, Reed JI, Walker AM. Body weight, body mass index, and incident symptomatic osteoarthritis of the hand, hip, and knee Epidemiology 1999; 10(2):161-6.

(31) Sayer AA, Poole J, Cox V, Kuh D, Hardy R, Wadsworth M et al. Weight from birth to 53 years: a longitudinal study of the influence on clinical hand osteoarthritis Arthritis Rheum 2003; 48(4):1030-3.

(32) Solovieva S, Vehmas T, Riihimaki H, Takala EP, Murtomaa H, Luoma K et al. Finger osteoarthritis and differences in dental work tasks J Dent Res 2006; 85(4):344-8.

(33) Sonne-Holm S, Jacobsen S. Osteoarthritis of the first carpometacarpal joint: a study of radiology and clinical epidemiology. Results from the Copenhagen Osteoarthritis Study Osteoarthritis Cartilage 2006; 14(5):496-500.

(34) Sowers M, Lachance L, Hochberg M, Jamadar D. Radiographically defined osteoarthritis of the hand and knee in young and middle-aged African American and Caucasian women Osteoarthritis and Cartilage 2000; 8(2):69-77.

(35) Sowers MF, Hochberg M, Crabbe JP, Muhich A, Crutchfield M, Updike S. Association of bone mineral density and sex hormone levels with osteoarthritis of the hand and knee in premenopausal women

Am J Epidemiol 1996; 143(1):38-47.

(36) Szoeke CE, Cicuttini FM, Guthrie JR, Clark MS, Dennerstein L. Factors affecting the prevalence of osteoarthritis in healthy middle-aged women: data from the longitudinal Melbourne Women's Midlife Health Project Bone 2006; 39(5):1149-55.

(37) Acheson RM, Collart AB. New Haven survey of joint diseases. XVII. Relationship between some systemic characteristics and osteoarthrosis in a general population. Ann Rheum Dis 1975; 34(5):379-87.

(38) Engel A. Osteoarthritis and Body measurements. Vital and Health Statistics . 1968. Washington, D.C. Ref Type: Generic 
(39) Hart DJ, Spector TD. The relationship of obesity, fat distribution and osteoarthritis in women in the general population: the Chingford Study. J Rheumatol 1993; 20(2):3315.

(40) KELLGREN JH, LAWRENCE JS. Osteo-arthrosis and disk degeneration in an urban population. Ann Rheum Dis 1958; 17(4):388-97.

(41) Sowers M, Zobel D, Weissfeld L, Hawthorne VM, Carman W. Progression of osteoarthritis of the hand and metacarpal bone loss. A twenty-year followup of incident cases. Arthritis Rheum 1991; 34(1):36-42.

(42) van Saase JL, van Romunde LK, Cats A, Vandenbroucke JP, Valkenburg HA. Epidemiology of osteoarthritis: Zoetermeer survey. Comparison of radiological osteoarthritis in a Dutch population with that in 10 other populations. Ann Rheum Dis 1989; 48(4):271-80.

(43) Obesity: preventing and managing the global epidemic. Report of a WHO Consultation. Geneva, World Health Organization, 2000 (WHO Technical Report Series, No. 894). 2008.

Ref Type: Generic

(44) Atkins D, Best D, Briss PA, Eccles M, Falck-Ytter Y, Flottorp S et al. Grading quality of evidence and strength of recommendations BMJ 2004; 328(7454):1490.

(45) Pottie P, Presle N, Terlain B, Netter P, Mainard D, Berenbaum F. Obesity and osteoarthritis: more complex than predicted! Ann Rheum Dis 2006; 65(11):1403-5.

(46) Dumond H, Presle N, Terlain B, Mainard D, Loeuille D, Netter P et al. Evidence for a key role of leptin in osteoarthritis. Arthritis Rheum 2003; 48(11):3118-29.

(47) Conaghan PG, Vanharanta H, Dieppe PA. Is progressive osteoarthritis an atheromatous vascular disease?

Ann Rheum Dis 2005; 64(11):1539-41.

(48) DeGroot J. The AGE of the matrix: chemistry, consequence and cure. Curr Opin Pharmacol 2004; 4(3):301-5. 


\section{Appendices (online supplemental files)}

Appendix I: Search strategies used and search results

\begin{tabular}{|c|c|c|c|}
\hline & Key Words & $\begin{array}{l}\text { Number of } \\
\text { Articles }\end{array}$ & $\begin{array}{l}\text { Unique } \\
\text { Articles }\end{array}$ \\
\hline Pubmed & $\begin{array}{l}\text { (obesity OR obese OR overweight OR adiposity } \\
\text { OR fat OR BMI OR body mass index OR Body Fat } \\
\text { Distribution) AND (osteoarthritis OR arthritis OR } \\
\text { arthrosis OR osteoarthrosis OR osteoarthrit* OR } \\
\text { arthriti* OR arthros* OR osteoarthros* OR } \\
\text { osteoartrit* OR artriti* OR artros* OR } \\
\text { osteoartros*) AND (hand OR hands OR Fingers } \\
\text { OR finger OR Thumb OR thumbs OR Metacarpus } \\
\text { OR Wrist OR wrists OR Hand Deformities OR } \\
\text { hand joints OR hand bones OR hand injuries) }\end{array}$ & 306 & 306 \\
\hline Web of Science & $\begin{array}{l}\text { (obes* OR overweight* OR adipos* OR fat OR } \\
\text { BMI OR "body mass index") AND (osteoarthr* } \\
\text { OR arthriti* OR arthros* OR osteoartr* OR artriti* } \\
\text { OR artros*) AND (hand OR hands OR Finger* OR } \\
\text { Thumb* OR Metacarp* OR Wrist*) }\end{array}$ & 248 & 90 \\
\hline CINAHL & $\begin{array}{l}\text { (exp Obesity/ OR exp Body Mass Index/ OR } \\
\text { Adipose Tissue Distribution/ OR exp Adipose } \\
\text { tissue/ OR (obesity OR obese OR overweight OR } \\
\text { adiposity OR fat OR BMI OR body mass } \\
\text { index).mp) AND (Exp osteoarthritis/ OR exp } \\
\text { Arthritis/ OR (osteoarthritis OR arthritis OR } \\
\text { arthrosis OR osteoarthrosis OR osteoarthrit* OR } \\
\text { arthriti* OR arthros* OR osteoarthros* OR } \\
\text { osteoartrit* OR artriti* OR artros* OR } \\
\text { osteoartros*).mp) AND (exp hand/ OR exp Hand } \\
\text { deformities/ OR exp Hand injuries/ OR Hand }\end{array}$ & 25 & 6 \\
\hline
\end{tabular}


surgery/ OR Hand therapy/ OR (hands OR Fingers

OR finger OR Thumb OR thumbs OR Metacarpus

OR Wrist OR wrists).mp)

EMBASE

(exp Obesity/ OR exp Adipose Tissue/ OR body

fat/ or body mass/ OR Body Fat Distribution/ OR

(obesity OR obese OR overweight OR adiposity

OR fat OR BMI OR body mass index OR Body Fat

Distribution).mp) AND (Osteoarthritis/ OR exp

Arthritis/ OR (osteoarthrit* OR arthriti* OR

arthros* OR osteoarthros* OR osteoartrit* OR

artriti* OR artros* OR osteoartros*).mp) AND

(exp Hand/ OR (hand OR hands OR Fingers OR

finger OR Thumb OR thumbs OR Metacarpus OR

Wrist OR wrists).mp) 
Appendix II: Explanation of the criteria used for assessment of methodological quality of included studies.

$\begin{array}{lll}\text { Item } & \text { Criteria } & \text { Applicable for }\end{array}$

Study population: Definition of Study population

1. Sufficient description of characteristics of study groups

$\mathrm{C} / \mathrm{CC} / \mathrm{CS}$

A ' 1 ' is given when a paper describes at least setting and time

period of the study, ages of the patients (and its range) and man:

woman ratio.

Study Population: Selection Bias

2. Selected at time point before disease was present

A ' 1 ' is given when patients were included before the outcome (hand OA) was present.

Selected at uniform point

$\mathrm{CC} / \mathrm{CS}$

A ' 1 ' is given when case and control were selected at the same time point concerning disease.

3. Clear description of selection of study subjects.

When a paper described how the study subjects were selected from the population level to the study level, a ' 1 ' will be given.

4. Cases and controls were drawn from the same population.

$\mathrm{CC}$

This is to exclude the possibility of selection bias.

5.

Participation rate $\geq \mathbf{8 0} \%$ for study groups.

$\mathrm{C} / \mathrm{CC} / \mathrm{CS}$

Eighty per cent was an arbitrary margin chosen to determine the quality of the selection of study subjects.

Assessment of overweight as risk factor

6.

7.
Weight was measured identical for cases and controls.

Weight was assessed prior to outcome.

In the sequence of assessing, when weight was measured before

hand OA was diagnosed, a '1' will be given. In most studies where
CC

C/CC/CS 
diagnosis of hand OA was made based on radiograph, a ' 1 ' will

also be given.

Assessment of the outcome: Hand Osteoarthritis

8.

Presence of hand OA was according to valid definition (1-3)

$\mathrm{C} / \mathrm{CC} / \mathrm{CS}$ and the classification was standardized.(4-6)

ACR criteria (4) did not request radiographic findings in making a diagnosis of hand OA, whereas EULAR recommendation (3)

proposed that multiple features on hand radiographs is adequate to make a diagnosis hand OA. A ' 1 ' will than given for a study which used ACR criteria or standardized radiological criteria for hand OA, like those from Kellgren and Lawrence (7), Kallman (5) and $\operatorname{OARSI}(8)$.

9.

\section{Hand OA assessment was blinded}

A ' 1 ' is given if the observers when making a diagnosis (by reading patient's chart) or reading the radiograph did not aware of patients' weigh or body composite.

10. Presence of hand OA was assessed reproducibly A ' 1 ' is given if hand $O A$ was assessed repeatedly at least in a subgroup, whether by the same observer or different observers.

11. Hand OA was assessed identical in cases and controls A ' 1 ' is given if assessment of hand OA status was the same in controls as in cases.

\section{Follow-up}

12.

\section{Prospective study design was used}

A ' 1 ' is given when a study measured the exposure (weight in this case) before the outcomes hand OA. Cross-sectional study will always scored ' $O$ ' on this item.

13.

\section{Follow up time $\geq 3$ years}

Three years are arbitrary margin to say about the acceptable duration of follow-up. 
14.

No difference in withdrawal in both groups

15.

Information on completers vs. withdrawals

$\mathrm{C}$

Analysis and Data Presentation

16.

Weight distribution was given

$\mathrm{C} / \mathrm{CC} / \mathrm{CS}$

A '1'is given if the paper describes the distribution of weight or

BMI of the study population.

17.

Sufficient information on association sizes were given

$\mathrm{C} / \mathrm{CC} / \mathrm{CS}$

18.

Appropriate analysis techniques were used

$\mathrm{C} / \mathrm{CC} / \mathrm{CS}$

19.

Adjusted for at least age and gender

$\mathrm{C} / \mathrm{CC} / \mathrm{CS}$ 
Appendix III. Details of the studies included, in order of study design hierarchy and their quality score

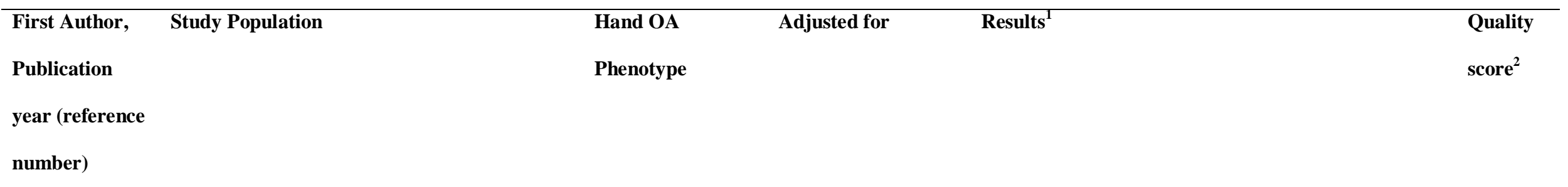

\section{Cohort studies}

Carman, 1994

General population from Tecumseh, USA

(Tecumseh Community Health Study)

$\mathrm{n}=588$ males and 688 females.

Age at follow-up: 50-74 years.

Follow-up duration: 23 years.

Szoeke, 2006

Females from general population in Melbourne

(Melbourne Women's Midlife Health Project)

$\mathrm{n}=224$

Mean age at follow up: 59 years.

Follow-up duration: 11 years.
Radiographic

Age, gender and

OA in any hand joint:

(K\&L)

Radiographic

(OARSI)

OA per unit BMI $\left(\mathrm{kg} / \mathrm{m}^{2}\right)$ increase, RR $1.02(0.9-1.1)$ smoking.

Age, gender,

hormone therapy,

Osteophytes or JSN in any hand joint:

Ideal weight, RR 1.0 (index)

$\geq 20 \%$ above ideal weight, RR 3.12 (1.65-5.88)

physical activity,

smoking 


$\begin{array}{ll}\text { Cicuttini, } & \text { Female twins from } 2 \text { sources of volunteers: twin } \\ 1996(11) & \text { registers and twins recruited by phone in } \\ & \text { London, UK. } \\ & \text { Case: osteophytes on radiograph ( } \mathrm{n}=78 \text { for DIP, } \\ & 43 \text { for PIP and } 82 \text { for } 1^{\text {st }} \text { CMC) } \\ & \text { Control: sib pairs with no radiolographic OA } \\ & \text { Mean age: } 58 \text { years. }\end{array}$

Oliveria, 1999 Females from general practice in Worchester

\section{USA (Fallon Community Health Plan)}

Case: hand OA $(\mathrm{n}=39)$

Control: females, matched by closest date of

birth $(n=39)$

Mean age 61 years.

Kujala, 1999

Finnish Twin Cohort, Finland

(13)

73 twins discordant for hand OA

Age: $39-66$ years.
Gender, menopausal OA per unit BMI $\left(\mathrm{kg} / \mathrm{m}^{2}\right)$ increase:

(Kallman)

status, age of

DIP, OR 1.07 (0.91 to 1.25$)$

menopause,

PIP, OR 1.15 ( 0.9 to 1.45$)$

hysterectomy, use of

$1^{\text {st }} \mathrm{CMC}$, OR 1.30 (1.06 to 1.59$)$

hormone replacement

therapy, smoking,

physical activity

Clinical (ACR),

Age, gender, estrogen

OA in any hand joint:

supported by

radiographic OA

therapy, smoking,

$\mathrm{BMI} \leq 23.80$, OR 1

number of Fallon

BMI 23.81 - 28.60, OR 5.4 (0.9 to 31.3)

featrures

health contacts

BMI > 28.6, OR 8.3 (1.2 to 56.5)

Self-reported

Age, gender

physican-based
'No differences in BMI among twin pairs discordant for

\section{Cross-sectional studies}


Sayer, 2003

$$
\text { General population followed since }
$$

$\mathrm{n}=1467$ males and 1519 females

Cross- sectional analysis at age of 53 years

\section{Dahagin, 2007}

\section{General population of Ommoord, the}

(15)

Netherlands (Rotterdam Study)

$\mathrm{n}=1499$ males and 2086 females

Mean age: 66 years.

$\begin{array}{ll}\text { Ding, } & \text { Female dentists and teacher in Helsinki, Finland. } \\ \text { 2008 (16) } & \mathrm{n}=532 \\ & \text { Mean age: } 54 \text { years. } \\ & \\ \text { Haara, } & \text { General population of Finland from } 69 \\ 2003 & \text { municipalities. } \\ \text { and Haara, } 2004 & \mathrm{n}=1560 \text { males and } 2035 \text { females } \\ \text { (17) } & \text { Age: older than } 30 \text { years. }\end{array}$

Age, gender, height, $\quad$ OA in any hand joint, men:

(Heberden's,

social class

Bouchard's nodes,

squaring at $1^{\text {st }}$

CMC)

Radiographic

$(\mathrm{K} \& \mathrm{~L})$

Age, gender,

smoking

(modified K\&L)

and clinical (pain)

Age, gender,

occupation, hand-

loading leisure-time

activities, occupation

Radiographic

$(\mathrm{K} \& \mathrm{~L})$

Age, gender,

educational level,

smoking, workload
Weight $\leq 74 \mathrm{~kg}$, OR 1

Weight $>91.8$, OR 1.4

'increasing OR with increasing adult weights'

OA in two of three groups (DIP, PIP, $1^{\text {st }} \mathrm{CMC}$ ) hand

77 joints:

BMI $<27.4$, OR 1

BMI >27.4, OR 1.4 (1.2 to 1.7$)$

Symptomatic OA in DIP joint:

BMI $<25$, OR 1 (index)

BMI 25-26.9, OR 1.62 (0.83 to 3.15)

$\mathrm{BMI} \geq 27, \mathrm{OR} 2.39$ (1.26 to 4.51$)$

OA in any hand joint (except CMC):
$\mathrm{BMI} \leq 20$, OR $0.50(0.31-0.83)$

BMI 20-24.9, OR 1 (index)

BMI 25.0-29.9 OR 1.17 (0.96-1.43)

BMI 30-34.9, OR 1.78 (1.37-2.33) 


$\begin{array}{lll}\text { Hart, } 1993 \text { (18) } & \text { Females from a large general practice in } & \text { Radiographic } \\ \text { Chingford, near London, UK (The Chingford } & \text { (K\&L) and clinical } \\ \text { Study) } & \text { (pain and stiffness) } \\ \mathrm{n}=985 & \end{array}$

Mean age: 54 years .

Jones, 2002 (19) Patients with OA and their family in Tasmania, Australia.

$\mathrm{n}=174$ males and 348 females

Mean age males: 53 years, females: 57 years.
$\mathrm{BMI} \geq 35$, OR $1.98(1.19-3.27)$

$\mathrm{OA}$ in $1^{\text {st }} \mathrm{CMC}$ joint:

BMI 20.0-24.9, OR 1 (index)

BMI $35, \mathrm{OR} \pm 2$

$\mathrm{BMI}<23.4$, OR 1 (index)

OA in DIP joint:

BMI $23.4-26.4$, OR 1.64 (0.84 to 3.21 )

BMI > 26.4, OR 1.71 (0.88 to 3.33)

OA in PIP joint:

BMI 23.4 - 26.4, OR 1.19 (0.39 to 3.62)

$\mathrm{BMI}>26.4$, OR 0.71 (0.22 to 2.29)

OA in CMC joint:

BMI $23.4-26.4$, OR1.68 (0.88 to 3.21$)$

BMI > 26.4, OR 1. 85 (0.96 to 3.56)

$\mathrm{BMI}<25$, OR 1

Radiographic OA in DIP joint:

$\mathrm{BMI} \geq 25, \mathrm{OR} 1.22$ (0.70 to 2.14$)$

Radiographic OA in CMC joint:

$\mathrm{BMI} \geq 25$, OR 0.99 (0.54 to 1.52$)$ 
Osteoarthritis Study)

$\mathrm{n}=242$ males and 397 females

Median age: 65 years.

Van Saase, General population of Zoetermeer, near the

Radiographic

$(\mathrm{K} \& \mathrm{~L})$

1071 males and 1097 females $(n=2168)$

Age: 45-64 years.

Andrianakos, General population of Greece (ESORDIG

$2006(22)$ study). Urban, suburban and rural.

$\mathrm{n}=4269$ males and 4471 females

Age: 19 to 99 years old, mean: 47 years.
Age, gender, physical OA in two or more IP joints:

exertion, and hip or

knee OA

Age and gender

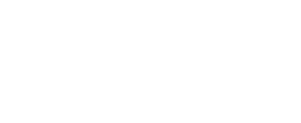

$$
\text { \%, }
$$

Clinical (ACR)

Age, gender,

education level,

occupation, alcohol

consumption,

cigarette smoking,

rural residence,

socioeconomic status.$$
\text { DIP (p } \leq 0.002), \operatorname{MCP}(p \leq 0.39), 1^{\text {st }} \mathrm{CMC}(\mathrm{p} \leq 0.30), \text { PIP }
$$$$
(\mathrm{p} \leq 0.001), \operatorname{CARP}(\mathrm{p} \leq 0.003), \text { wrist }(\mathrm{p} \leq 0.12)
$$

OA per unit BMI $\left(\mathrm{kg} / \mathrm{m}^{2}\right)$ increase, OR 1.02 (0.98 to 1.07)

$\mathrm{OA}$ in at least one of $1^{\text {st }} \mathrm{CMC}$ joint:

OA per unit BMI $\left(\mathrm{kg} / \mathrm{m}^{2}\right)$ increase, OR 1.01 (0.96 to 1.06)

$\widehat{\partial}$, association between overweight and OA :

$\operatorname{DIP}(\mathrm{p} \leq 0.001), \operatorname{MCP}(\mathrm{p} \leq 0.001), 1^{\text {st }} \mathrm{CMC}(\mathrm{p} \leq 0.15)$, wrist ( $\mathrm{p} \leq 0.29)$, PIP $(\mathrm{p} \leq 0.001), \mathrm{CARP}(\mathrm{p} \leq 0.06)$

, association between overweight and OA:

Clinical OA:
$\mathrm{BMI} \geq 30$, OR 1.3 (0.98 to1.8) 
Cvijetic, 2000

General population of Zagreb, Croatia

$\mathrm{n}=304$ males and 306 females

Mean age male and female: 63 years.

Sowers, 2000

Females from two cohorts: General population

of Michigan, USA (Michigan Bone Health

Study), $\mathrm{n}=510$ and volunteers from Study of

Women's Health Across the Nation, n=543

Age: 27-53 years, median: 44 years

Bergstrom, Seventy-year old People Study in Goteborg,

$1986(25) \quad$ Sweden

$\mathrm{n}=190$ males and 162 females

Cross-sectional analysis of 70 years (cohort 1),

75 years (cohort 2) and 79 years (cohort 3 )

Kalichman, General population of Chuvasa, Russia,

2005 (26) (Chuvasha Skeletal Aging). Agricultural.

$\mathrm{n}=663$ males and 605 females

Age males: 18-89 years, mean: 46.3 years and
Radiographic

(K\&L)

Radiographic

$(\mathrm{K} \& \mathrm{~L})$

Radiographic

$(\mathrm{K} \& \mathrm{~L})$

Radiographic

$(\mathrm{K} \& \mathrm{~L})$
Age, gender, duration $\quad \beta$ values of multiple regression analysis:

of postmenopause, $\quad$ DIP: $0.25, \mathrm{p}<0.001$, PIP: $0.08,1^{\text {st }} \mathrm{CMC}: 0.07$

cigarette smoking, $\quad$ : DIP: 0.17, PIP: 0.02, $1^{\text {st }}$ CMC: 0.02

blood pressure

Age, gender,

previous injury,

smoking

A in any hand joint:

OA per unit BMI $\left(\mathrm{kg} / \mathrm{m}^{2}\right)$ increase, OR 1.05 (1.03 to 1.08)

Age and gender

DIP, PIP, MCP II-V, MCPI, $1^{\text {st }} \mathrm{CMC}$ joints were assessed:

3: 'BMI was correlated to MCP I and IP I $(\mathrm{p}<0.05)$ but not with other joints'

Q: 'BMI was correlated with DIP $(\mathrm{p}<0.01)$ but not with other joints'

Correlation between overweight and OA: 0.11 
females 18-90 years, mean: 48.2 .

Grotle, 2008

General population of Ullensaker, near Oslo,

Norway. Rural.

$\mathrm{n}=1470$ males and 1796 females

Mean age: 45 years

Hochberg, 1993 Female volunteers in Baltimore (Baltimore

Longitudinal Study of Aging). Middle class

$\mathrm{n}=317$

Mean age: 55 years

Hochberg, 1991 Male volunteers in Baltimore (Baltimore

Longitudinal Study of Aging). Middle class.

$$
\mathrm{n}=888
$$

Mean age: 56 years

Sonne-Holm, General population of Osterbro, Copenhagen,

$2006(30)$

Denmark (Copenhagen City Health Study).

$\mathrm{n}=1295$ males and 2060 females.

Acheson, 1975 General population New Haven, Connecticut,

(31)
Self-reported

Radiographic

$(\mathrm{K} \& \mathrm{~L})$

Radiographic

(K\&L)

Radiographic

$(\mathrm{K} \& \mathrm{~L})$

Radiographic

$(\mathrm{K} \& \mathrm{~L})$
Age and gender

BMI 26-30 OR 1.00 (0.69 to 1.48 )

Age and gender

significantly different across grade of hand OA except

Age and gender

Not adjusted

'OA is associated with $\mathrm{K} \& \mathrm{~L}$ grade 2 to 3 ( $\mathrm{p}<0.0000)$ '

Gender
Self-reported OA:

BMI <20, OR 0.70 (0.24 to1.99)

BMI 20-25, OR 1 (index)

BMI > 30, OR 1.57 (0.93 to2.64)

'all independent variables (age, WHR, \% fat) were

BMI'

'the distribution of these residual values were not

significantly different by grade of hand osteoarthritis for

any of these independent variables (like BMI)'.

Difference on the average weight between subjects with

$\mathrm{OA}$ and without $\mathrm{OA}$ 
$\mathrm{n}=300$ males and 385 females

Age: older than 21 years.

Kellgren, 1958

Random sample of general population in Leigh,

UK. Urban.

$\mathrm{n}=204$ males and 277

Age: 55-64 years.

Engel, 1968

General population in USA

(Health Examination Survey I)

$\mathrm{n}=6672$

18-79 years
: 172.13 vs. $171.58 \mathrm{lbs}$, not significant

$: 143.96$ vs. $134.48, \mathrm{p}<0.01$

'DIP OA is associated with overweight males ( $\mathrm{p}<0.01)$

but no significant association on PIP, $1^{\text {st }} \mathrm{CMC}, \mathrm{MP}$ and wrists in both sexes.'

Association between Ponderal index (height divided by

the cubed root of weight) and hand OA for age groups:

ふૈ: 45-54 yr: p 0.01, 55-64 yr: -, 65-74 yr: p 0.05

१: 45-54 yr: p 0.0005, 55-64 yr: -, 65-74 yr: -

${ }^{1}$ in parentheses $95 \%$ confidence interval, ${ }^{2}$ quality score in per cent $(\%)$

Abbreviations: K\&L: Kellgren and Lawrence radiographs scoring system, OARSI: Osteoarthritis Research Society International scoring system, ACR: American College of

Rheumatology, DIP: distal interphalangeal joints, PIP: proximal interphalangeal joints, MCP: metacarpophalangeal joints, CMC: carpometacarpal joints, $1^{\text {st }}$ CMC:

carpometacarpal joints of the thumb, BMI: body mass index. 
Appendix IV. Study quality assessment scores of two reviewers (1: present, 0: absent or no information). Scores solved by discussion are in italics.

\begin{tabular}{|c|c|c|c|c|c|c|c|c|c|c|c|c|c|c|c|c|c|c|c|c|c|c|}
\hline & & & & & & & & & & Crite & & & & & & & & & & & & \\
\hline & 1 & 2 & 3 & 4 & 5 & 6 & 7 & 8 & 9 & 10 & 11 & 12 & 13 & 14 & 15 & 16 & 17 & 18 & 19 & Total & Quality score (\%) & \\
\hline \multicolumn{23}{|l|}{ Cohort } \\
\hline Carman (9) & 1 & 1 & 1 & na & 0 & na & 1 & 1 & 0 & 1 & na & 1 & 1 & 1 & 1 & 1 & 1 & 1 & 1 & 14 & 88 & \\
\hline Szoeke (10) & 1 & 1 & 1 & na & 0 & na & 1 & 1 & 1 & 0 & na & 1 & 1 & 0 & 0 & 1 & 1 & 1 & 1 & 12 & 75 & \\
\hline$\%$ paper met the criteria & 100 & 100 & 100 & na & 0 & na & 100 & 100 & 50 & 50 & na & 100 & 100 & 50 & 50 & 100 & 100 & 100 & 100 & & & \\
\hline \multicolumn{23}{|l|}{ Case-control } \\
\hline Cicuttini (11) & 1 & 0 & 1 & 1 & 1 & 1 & 1 & 1 & 1 & 1 & 1 & 0 & na & na & na & 1 & 1 & 1 & 1 & 14 & 88 & \\
\hline Oliveria (12) & 1 & 1 & 1 & 1 & 0 & 1 & 1 & 1 & 1 & 0 & 0 & 0 & na & na & na & 1 & 1 & 1 & 1 & 12 & 75 & \\
\hline$\%$ paper met the criteria & 67 & 33 & 100 & 100 & 33 & 100 & 100 & 67 & 67 & 33 & 67 & 0 & na & na & na & 67 & 67 & 100 & 100 & & & \\
\hline \multicolumn{22}{|l|}{ Cross-sectional } & \\
\hline Acheson (31) & 0 & 0 & 0 & na & 0 & na & 1 & 1 & 0 & 0 & na & 0 & na & na & na & 0 & 1 & 0 & 1 & 4 & 31 & \\
\hline Andrianakos (22) & 1 & 1 & 1 & na & 1 & na & 0 & 1 & 0 & 1 & na & 0 & na & na & na & 0 & 1 & 1 & 1 & 9 & 69 & \\
\hline Bergstrom (25) & 1 & 0 & 1 & na & 0 & na & 1 & 1 & 1 & 1 & na & 0 & na & na & na & 0 & 0 & 1 & 1 & 8 & 62 & 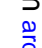 \\
\hline Cvijetic (23) & 1 & 0 & 0 & na & 0 & na & 1 & 1 & 1 & 1 & na & 0 & na & na & na & 1 & 1 & 1 & 1 & 9 & 69 & \\
\hline Dahagin (15) & 1 & 0 & 1 & na & 0 & na & 1 & 1 & 1 & 1 & na & 0 & na & na & na & 1 & 1 & 1 & 1 & 10 & 77 & \\
\hline Engel (33) & 0 & 0 & 0 & na & 0 & na & 1 & 0 & 0 & 0 & na & 0 & na & na & na & 0 & 1 & 0 & 1 & 3 & 23 & \\
\hline Grotle (27) & 1 & 0 & 1 & na & 0 & na & 0 & 0 & 0 & 0 & na & 0 & na & na & na & 1 & 1 & 1 & 1 & 6 & 46 & \\
\hline Haara (17) & 1 & 0 & 1 & na & 0 & na & 1 & 1 & 1 & 1 & na & 0 & na & na & na & 1 & 1 & 1 & 1 & 10 & 77 & \\
\hline Hart (18) & 1 & 0 & 1 & na & 0 & na & 1 & 1 & 1 & 1 & na & 0 & na & na & na & 1 & 1 & 1 & 1 & 10 & 77 & \\
\hline Hochberg (29) & 1 & 0 & 0 & na & 0 & na & 1 & 1 & 0 & 0 & na & 0 & na & na & na & 1 & 1 & 0 & 1 & 6 & 46 & \\
\hline Hochberg (28) & 1 & 0 & 0 & na & 0 & na & 1 & 1 & 0 & 0 & na & 0 & na & na & na & 1 & 1 & 0 & 1 & 6 & 46 & \\
\hline Jones (19) & 1 & 0 & 1 & na & 0 & na & 1 & 1 & 1 & 1 & na & 0 & na & na & na & 1 & 1 & 1 & 1 & 10 & 77 & \\
\hline Kalichman (26) & 1 & 0 & 0 & na & 0 & na & 1 & 1 & 0 & 1 & na & 0 & na & na & na & 1 & 1 & 1 & 1 & 8 & 62 & \\
\hline Kellgren (32) & 1 & 0 & 0 & na & 0 & na & 1 & 1 & 0 & 1 & na & 0 & na & na & na & 0 & 0 & 0 & 0 & 4 & 31 & \\
\hline Kessler (20) & 1 & 0 & 1 & na & 1 & na & 1 & 1 & 1 & 0 & na & 0 & na & na & na & 1 & 1 & 1 & 1 & 10 & 77 & \\
\hline Sayer (14) & 1 & 1 & 1 & na & 0 & na & 1 & 1 & 0 & 1 & na & 0 & na & na & na & 1 & 1 & 1 & 1 & 10 & 77 & \\
\hline Sonne-Holm (30) & 1 & 0 & 0 & na & 1 & na & 0 & 1 & 1 & 1 & na & 0 & na & na & na & 0 & 0 & 0 & 0 & 5 & 38 & \\
\hline Sowers (24) & 1 & 0 & 1 & na & 0 & na & 1 & 1 & 0 & 1 & na & 0 & na & na & na & 1 & 1 & 1 & 1 & 9 & 69 & \\
\hline $\begin{array}{l}\text { van Saase (21) } \\
\% \text { paper met the criteria }\end{array}$ & $\begin{array}{r}1 \\
90\end{array}$ & $\begin{array}{r}0 \\
10\end{array}$ & $\begin{array}{r}1 \\
60\end{array}$ & $\begin{array}{l}\text { na } \\
\text { na }\end{array}$ & $\begin{array}{r}0 \\
15\end{array}$ & $\begin{array}{l}\text { na } \\
\text { na }\end{array}$ & $\begin{array}{r}1 \\
85\end{array}$ & $\begin{array}{r}1 \\
90\end{array}$ & $\begin{array}{r}1 \\
50\end{array}$ & $\begin{array}{r}1 \\
70\end{array}$ & $\begin{array}{l}\text { na } \\
\text { na }\end{array}$ & $\begin{array}{l}0 \\
0\end{array}$ & $\begin{array}{l}\text { na } \\
\text { na }\end{array}$ & $\begin{array}{l}\text { na } \\
\text { na }\end{array}$ & $\begin{array}{l}\text { na } \\
\text { na }\end{array}$ & $\begin{array}{r}1 \\
70\end{array}$ & $\begin{array}{r}1 \\
85\end{array}$ & $\begin{array}{r}1 \\
70\end{array}$ & $\begin{array}{r}1 \\
90\end{array}$ & 10 & 77 & \\
\hline
\end{tabular}




\section{Reference List}

(1) Altman R, Alarcon G, Appelrouth D, Bloch D, Borenstein D, Brandt K et al. The American College of Rheumatology criteria for the classification and reporting of osteoarthritis of the hand. Arthritis Rheum 1990; 33(11):1601-10.

(2) Hart DJ, Spector TD. Definition and epidemiology of osteoarthritis of the hand: a review. Osteoarthritis Cartilage 2000; 8 Suppl A:S2-S7.

(3) Zhang W, Doherty M, Leeb BF, Alekseeva L, Arden NK, Bijlsma JW et al. EULAR evidence based recommendations for the diagnosis of hand osteoarthritis - report of a task force of the EULAR Standing Committee for International Clinical Studies Including Therapeutics (ESCISIT). Ann Rheum Dis 2008.

(4) Altman RD. Criteria for Classification of Clinical Osteoarthritis. Journal of Rheumatology 1991; 18:10-2.

(5) Kallman DA, Wigley FM, Scott WW, Jr., Hochberg MC, Tobin JD. New radiographic grading scales for osteoarthritis of the hand. Reliability for determining prevalence and progression. Arthritis Rheum 1989; 32(12):1584-91.

(6) Murphy WA, Altman RD. Updated Osteoarthritis Reference-Standard. Journal of Rheumatology 1995; 22:56-9.

(7) KELLGREN JH, LAWRENCE JS. Radiological assessment of osteo-arthrosis Ann Rheum Dis 1957; 16(4):494-502.

(8) Altman RD, Gold GE. Atlas of individual radiographic features in osteoarthritis, revised Osteoarthritis Cartilage 2007; 15 Suppl A:A1-56.

(9) Carman WJ, Sowers M, Hawthorne VM, Weissfeld LA. Obesity as a risk factor for osteoarthritis of the hand and wrist: a prospective study. Am J Epidemiol 1994; 139(2):119-29.

(10) Szoeke CE, Cicuttini FM, Guthrie JR, Clark MS, Dennerstein L. Factors affecting the prevalence of osteoarthritis in healthy middle-aged women: data from the longitudinal Melbourne Women's Midlife Health Project Bone 2006; 39(5):1149-55.

(11) Cicuttini FM, Baker JR, Spector TD. The association of obesity with osteoarthritis of the hand and knee in women: a twin study. J Rheumatol 1996; 23(7):1221-6.

(12) Oliveria SA, Felson DT, Cirillo PA, Reed JI, Walker AM. Body weight, body mass index, and incident symptomatic osteoarthritis of the hand, hip, and knee Epidemiology 1999; 10(2):161-6. 
(13) Kujala UM, Leppavuori J, Kaprio J, Kinnunen J, Peltonen L, Koskenvuo M. Joint-specific twin and familial aggregation of recalled physician diagnosed osteoarthritis

178. Twin Res 1999; 2(3):196-202.

(14) Sayer AA, Poole J, Cox V, Kuh D, Hardy R, Wadsworth M et al. Weight from birth to 53 years: a longitudinal study of the influence on clinical hand osteoarthritis 132. Arthritis Rheum 2003; 48(4):1030-3.

(15) Dahaghin S, Bierma-Zeinstra SM, Koes BW, Hazes JM, Pols HA. Do metabolic factors add to the effect of overweight on hand osteoarthritis? The Rotterdam Study. Ann Rheum Dis 2007; 66(7):916-20.

(16) Ding H. Association between overweight and dip osteoarthritis among middleaged Finnish female dentists and teachers. Obesity Research and Clinical Practice 2008; 2(1):61-8.

(17) Haara MM, Manninen P, Kroger H, Arokoski JP, Karkkainen A, Knekt P et al. Osteoarthritis of finger joints in Finns aged 30 or over: prevalence, determinants, and association with mortality Ann Rheum Dis 2003; 62(2):151-8.

(18) Hart DJ, Spector TD. The relationship of obesity, fat distribution and osteoarthritis in women in the general population: the Chingford Study. J Rheumatol 1993; 20(2):331-5.

(19) Jones G, Cooley HM, Stankovich JM. A cross sectional study of the association between sex, smoking, and other lifestyle factors and osteoarthritis of the hand 363. Journal of Rheumatology 2002; 29(8):1719-24.

(20) Kessler S, Stove J, Puhl W, Sturmer T. First carpometacarpal and interphalangeal osteoarthritis of the hand in patients with advanced hip or knee OA. Are there differences in the aetiology?

118. Clin Rheumatol 2003; 22(6):409-13.

(21) van Saase JL, van Romunde LK, Cats A, Vandenbroucke JP, Valkenburg HA. Epidemiology of osteoarthritis: Zoetermeer survey. Comparison of radiological osteoarthritis in a Dutch population with that in 10 other populations. Ann Rheum Dis 1989; 48(4):271-80.

(22) Andrianakos AA, Kontelis LK, Karamitsos DG, Aslanidis SI, Georgountzos AI, Kaziolas GO et al. Prevalence of symptomatic knee, hand, and hip osteoarthritis in Greece. The ESORDIG study. J Rheumatol 2006; 33(12):2507-13.

(23) Cvijetic S, Campbell L, Cooper C, Kirwan J, Potocki K. Radiographic osteoarthritis in the elderly population of Zagreb: distribution, correlates, and the pattern of joint involvement. Croat Med J 2000; 41(1):58-63. 
(24) Sowers M, Lachance L, Hochberg M, Jamadar D. Radiographically defined osteoarthritis of the hand and knee in young and middle-aged African American and Caucasian women

Osteoarthritis and Cartilage 2000; 8(2):69-77.

(25) Bergstrom G, Bjelle A, Sundh V, Svanborg A. Joint disorders at ages 70, 75 and 79 years--a cross-sectional comparison. Br J Rheumatol 1986; 25(4):333-41.

(26) Kalichman L, Malkin I, Kobyliansky E. Association between physique characteristics and hand skeletal aging status

76. Am J Phys Anthropol 2005; 128(4):889-95.

(27) Grotle M, Hagen KB, Natvig B, Dahl FA, Kvien TK. Prevalence and burden of osteoarthritis: results from a population survey in norway

J Rheumatol 2008; 35(4):677-84.

(28) Hochberg MC, Lethbridge-Cejku M, Scott WW, Jr., Plato CC, Tobin JD. Obesity and osteoarthritis of the hands in women

Osteoarthritis Cartilage 1993; 1(2):129-35.

(29) Hochberg MC, Lethbridge-Cejku M, Plato CC, Wigley FM, Tobin JD. Factors associated with osteoarthritis of the hand in males: data from the Baltimore Longitudinal Study of Aging Am J Epidemiol 1991; 134(10):1121-7.

(30) Sonne-Holm S, Jacobsen S. Osteoarthritis of the first carpometacarpal joint: a study of radiology and clinical epidemiology. Results from the Copenhagen Osteoarthritis Study Osteoarthritis Cartilage 2006; 14(5):496-500.

(31) Acheson RM, Collart AB. New Haven survey of joint diseases. XVII. Relationship between some systemic characteristics and osteoarthrosis in a general population. Ann Rheum Dis 1975; 34(5):379-87.

(32) KELLGREN JH, LAWRENCE JS. Osteo-arthrosis and disk degeneration in an urban population. Ann Rheum Dis 1958; 17(4):388-97.

(33) Engel A. Osteoarthritis and Body measurements. Vital and Health Statistics . 1968. Washington, D.C.

Ref Type: Generic 


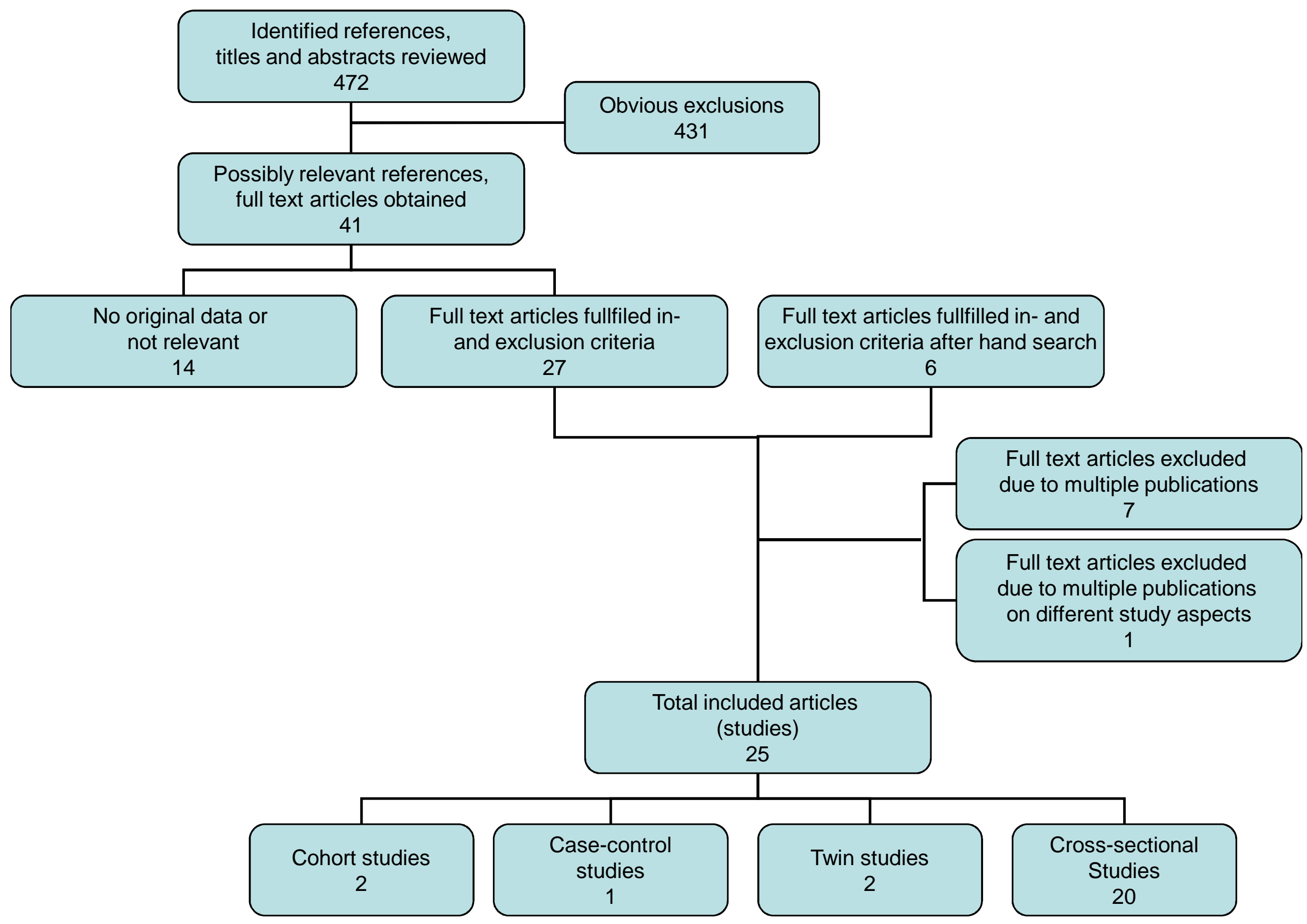




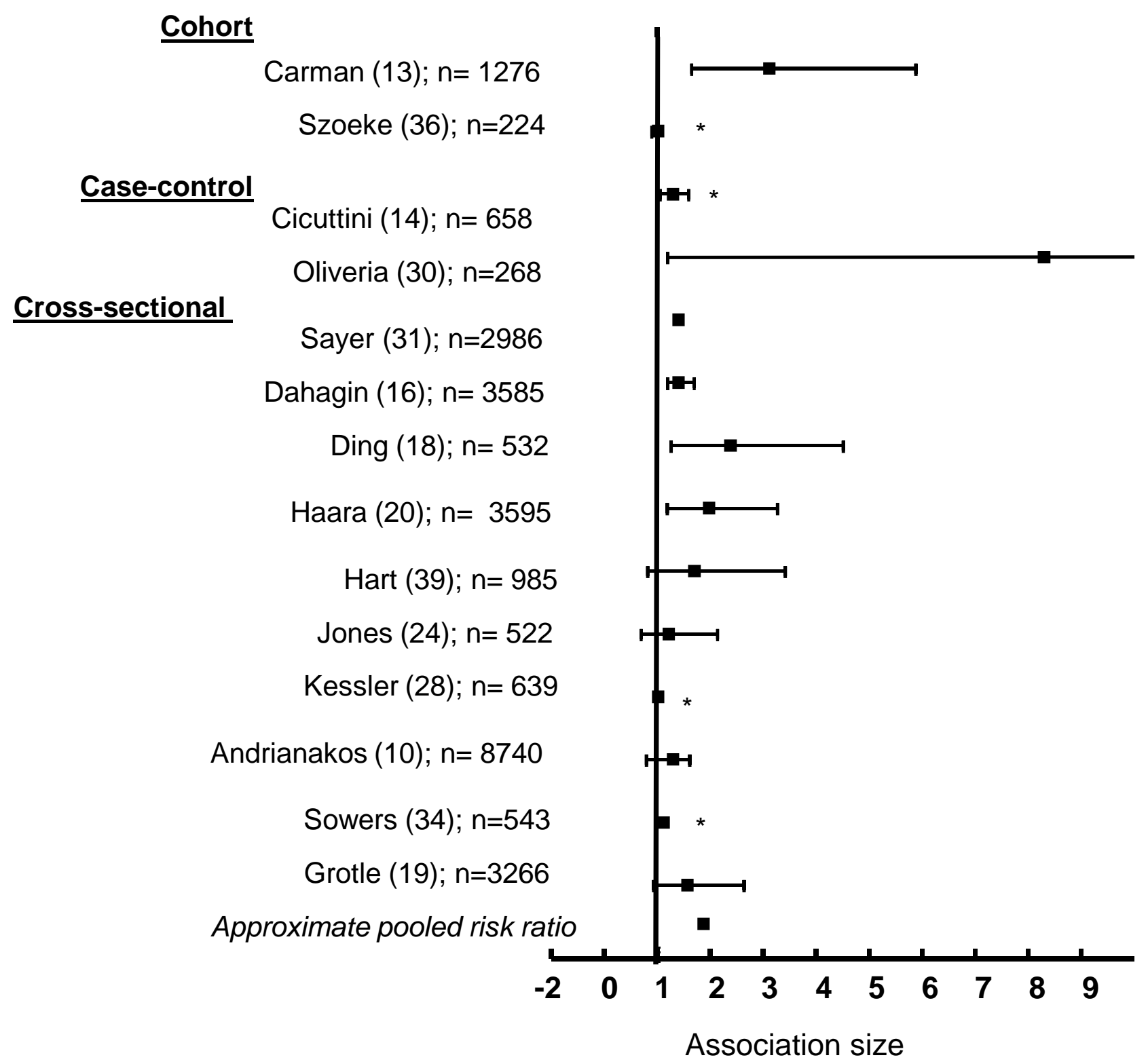




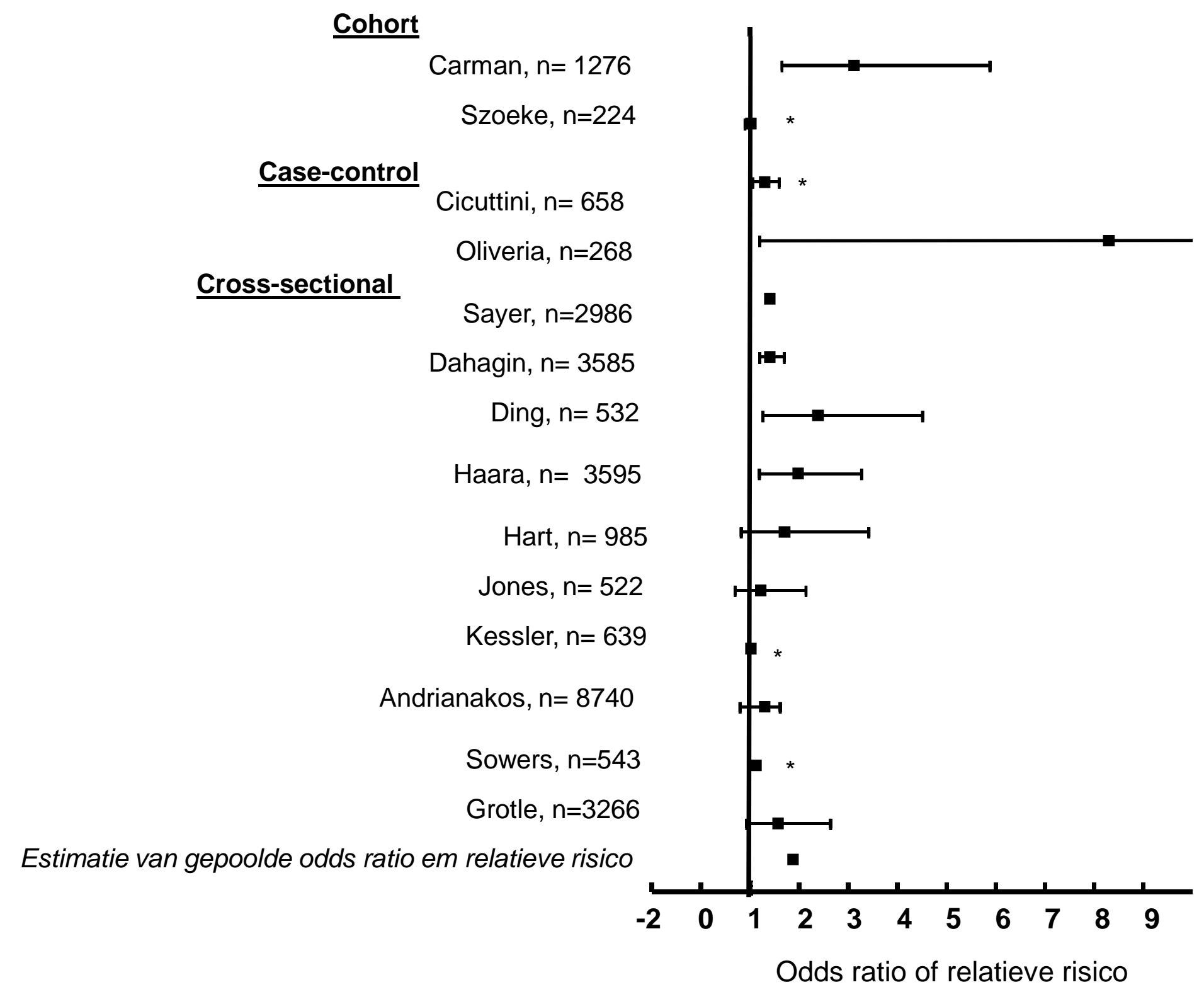




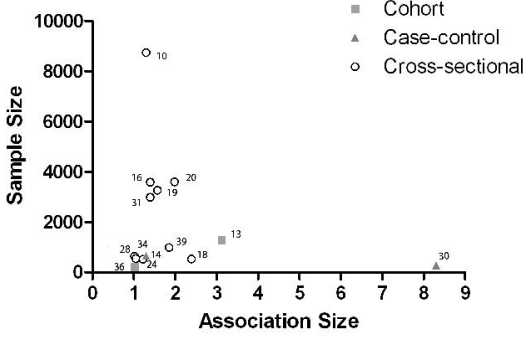

